\title{
Subarachnoid haemorrhage in pseudoxanthoma elasticum
}

\author{
N. G. K. Sharma \\ M.D. \\ P. C. BEOHAR* \\ M.B.B.S., M.SC., Pн.D.
}

\author{
S. K. GHOSH \\ M.D., D.M.R.E. \\ P. S. GUPTA \\ M.D.
}

Departments of Medicine, Radiology and Pathology,
Goa Medical College, Panjim-Goa, India

\section{Summary}

A case of pseudoxanthoma elasticum presenting with the rare complication of subarachnoid haemorrhage is described.

\section{Introduction}

Pseudoxanthoma elasticum (PXE) is a rare heritable disorder of the connective tissue. Up to 1964, approximately 400 cases had been reported (Suerig and Siefert, 1964). The lesion involves mainly the skin, the eyes and the cardiovascular system, giving rise to diverse clinical manifestations. Most of the reports have highlighted the association of cutaneous changes with angioid streaks in the retina, gastro-intestinal haemorrhage and cardiovascular involvement. The neurological manifestations of PXE have not been reported as commonly. We report a patient with PXE who presented with subarachnoid haemorrhage.

\section{Case report}

A 35-year-old, single, Hindu male was admitted to the Goa Medical College Hospital, Panjim, on 29 April 1971, with the history of paralysis of the left side of the body of one day's duration. It was sudden in onset and was preceded by giddiness and intense headache. There was no history of unconsciousness, convulsions or fever. He did not complain of any skin lesions. There was no history of consanguinity of his parents. No other member of the family suffered from any obviously relevant illness.

On physical examination, the patient was moderately well nourished and ill-looking. The skin in the neck was lax, inelastic and thrown into folds (Fig. 1). There were small, soft, yellow papules distributed more or less parallel to the skin folds. Similar skin changes were also seen in the axillae, periumbilical area and groins (Fig. 2). Both the radial pulses and all the lower limb pulses were absent. The blood

* Present address: Department of Pathology, Maulana Azad Medical College, New Delhi, India. pressure in both arms was $200 / 120 \mathrm{mmHg}$ and was not recordable in the lower limbs.

On examination of the central nervous system, the patient was conscious. There was marked neck rigidity. The Kernig's sign was positive. There were signs of left hemiplegia. Fundus examination revealed bilateral macular degeneration, pigmentation around the right disc and chorio-retinitis on the left. There were no angioid streaks. Other systems were normal.

The routine urine examination was normal. Stools were positive for occult blood. The haemoglobin was $13 \mathrm{~g} / 100 \mathrm{ml}$, WBC $14,000 / \mathrm{mm}^{3}$. Bleeding and clotting times were within normal limits. The serums cholesterol was $160 \mathrm{mg} / 100 \mathrm{ml}$, blood urea $24 \mathrm{mg}$ $100 \mathrm{ml}$, and glucose $168 \mathrm{mg} / 100 \mathrm{ml}$. The blood VDRL test was negative. Lumbar puncture revealed a uniformly haemorrhagic cerebrospinal fluid and, on centrifuging, the supernatant fluid was xanthochromic. The cerebrospinal fluid biochemistry was within normal limits except for a slight increase in the protein content.

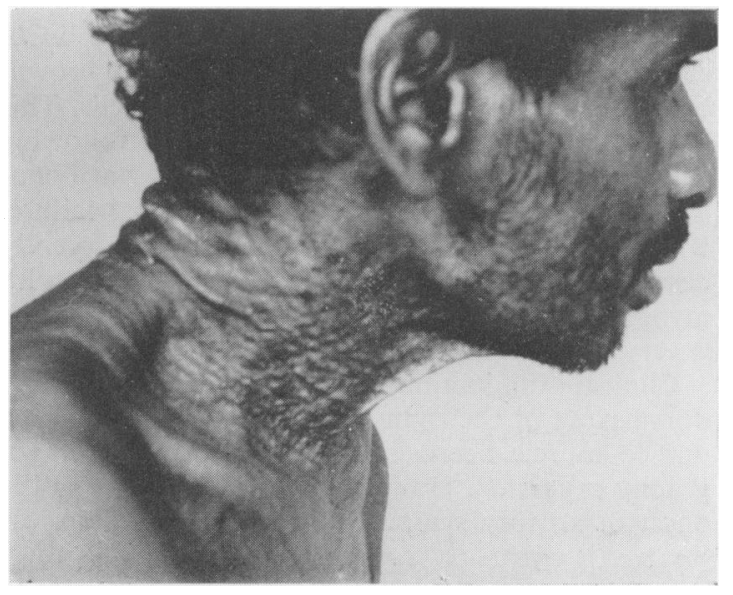

FIG. 1. The skin of the neck appears lax, inelastic and is thrown into folds. 


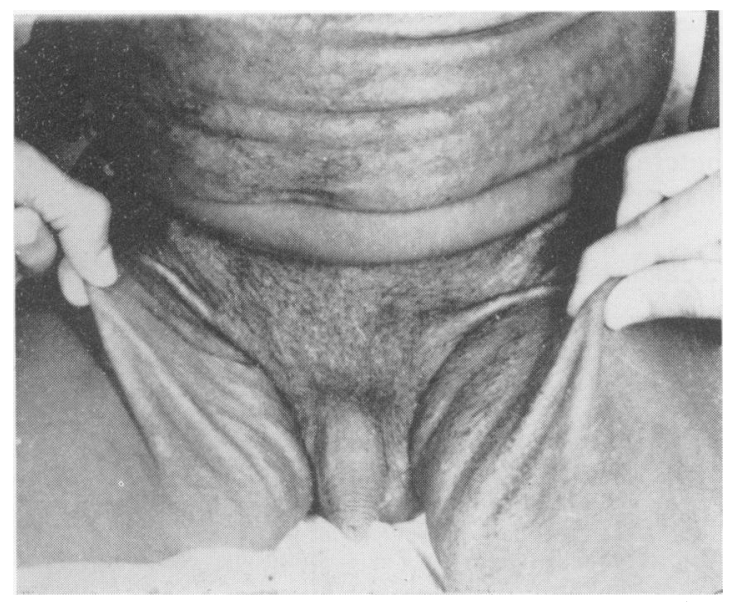

FIG. 2. The skin of the groin and peri-umbilical region shows lax inelastic folds which can easily be pinched.

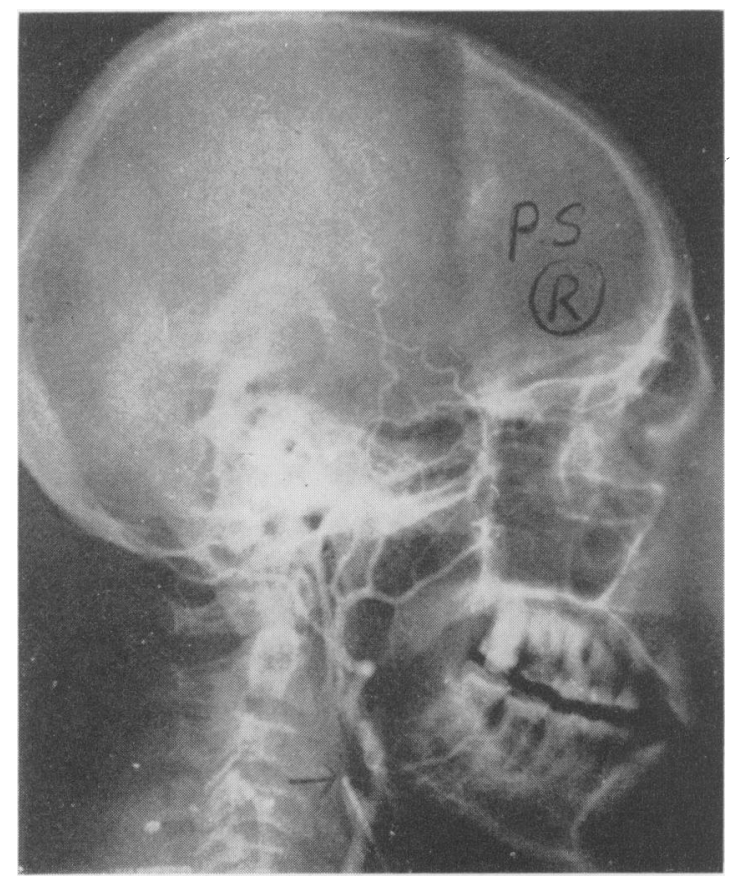

FIG. 3. Lateral picture of right carotid angiogram. The tip of the needle is seen just inside the origin of the internal carotid artery. The artery is not visualized.

The electrocardiogram showed evidence of left ventricular hypertrophy. X-ray of the chest revealed calcification of the skin of the neck and axillae, and a normal heart and lungs. X-rays of the extremities did not show calcification of arteries. Bilateral

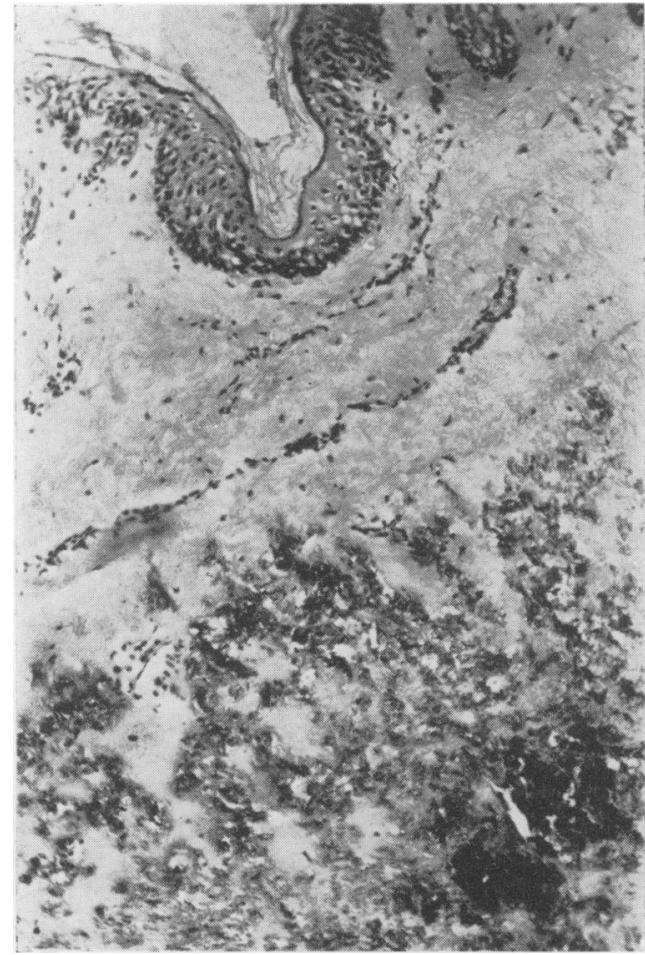

Fig. 4. Skin biopsy shows fragmentation of tissue in the middle dermis (haematoxylin and eosin $\times 100$ ).

carotid angiograms showed obliteration of the right carotid artery (Fig. 3) and generalized diminution in calibre of the left internal carotid artery. No aneurysms were seen.

When stained with haematoxylin and eosin, the skin biopsy specimen from the neck and axillae showed calcified fragments of tissue in the middle and lower dermis, a diagnostic feature of PXE (Fig. 4).

The patient made a good recovery, the cerebrospinal fluid returned to normal and he left the hospital, w ith residual hemiparesis.

\section{Comment}

PXE has a world-wide distribution. The disease is usually inherited as an autosomal dominant trait (Berlyne, Bulmer and Platt, 1961). There has been considerable controversy as to whether the basic disease process involves the elastic fibres or the collagen fibres. Recent reports have shown that the primary site of abnormality is the elastic tissue (Loria et al., 1957; Smith, Sams and Davidson, 1962; Huang et al., 1967).

In PXE, virtually every organ in the body can be affected (Loria et al., 1957). Our patient had changes 
mainly in the skin, cardiovascular and cerebrovascular systems. The cutaneous manifestations are small, soft and yellow papules arranged parallel to the skin lines and folds. In advanced cases the skin is thickened and hangs in loose, inelastic, redundant folds in the flexural areas, and has been described as 'plucked chicken-skin', 'crepe-like' skin, etc. Our patient had these advanced skin changes.

Cardiovascular abnormalities in PXE may be extensive and varied. Premature atherosclerosis in this disorder is due to elastic tissue degeneration and fragmentation in the media of the arteries leading to secondary deposition of calcium (Chong, 1970). These changes may result in weak or absent peripheral pulses and arterial insufficiency at various sites. Our patient had absent peripheral pulses, hypertension and evidence of left ventricular hypertrophy on the electrocardiogram. Hypertension is reported to be about three times more common in PXE than in the general population and is thought to be secondary to the involvement of renal glomeruli (Connor et al., 1961).

Internal haemorrhage is a common manifestation of PXE and is attributed to vascular degeneration of the affected viscera. The commonest site of bleeding is the upper gastro-intestinal tract, and the rare sites of haemorrhage are the nose, the gums, the respiratory tract, the genito-urinary tract and the subarachnoid space. Eddy and Farber (1962) reported gastro-intestinal haemorrhage in $13 \%$ and bleeding from various other organs in only about $3 \%$ of the cases reviewed by them. In our patient, the stools were positive for occult blood; but the interesting feature was that he presented with subarachnoid haemorrhage which is a rare manifestation in this disease. Bilateral carotid angiogram revealed generalized arterial involvement of the internal carotid system with complete obliteration of the right internal carotid artery but no obvious site of haemorrhage.

\section{Acknowledgment}

We are indebted to Dr H. Mazumdar, Dean of Goa Medical College, Panjim, India, for permitting us to report this case.

\section{References}

Berlyne, G.M., Bulmer, M.G. \& Platt, R.A. (1961) A study of the genetics of pseudoxanthoma elasticum. Quarterly Journal of Medicine, 30, 201.

Chong Hai TAy (1970) Pseudoxanthoma elasticum. Postgraduate Medical Journal, 46, 97.

Connor, J.P., Juergens, J.L., Perry, H.O., Haldenhorat, R.W. \& EdWARDS, J.E. (1961) Pseudoxanthoma elasticum and angioid streaks: a review of 106 cases. American Journal of Medicine, 30, 537.

EDDY, D.D. \& FARBER, E.E. (1962) Pseudoxanthoma elasticum internal manifestations: a report of cases and a statistical review of the literature. Archives of Dermatology, 86, 729.

Huang Shao-Nan, Steele, H.D., Kumar, G. \& Parker, J.O. (1967) Ultrastructural changes of elastic fibres in pseudoxanthoma elasticum: a study of histogenesis. Archives of Pathology, 83, 108.

Loria, P.R., Kennedy, C.B., Freeman, J.A. \& Henington V.M. (1957) Pseudoxanthoma elasticum: GronbladStrandberg syndrome. Archives of Dermatology, 76, 609.

SMith, G.J. JR, SAMS, W.M. \& Davidson, E.A. (1962) Pseudoxanthoma elasticum-histochemical and biochemical alterations. Archives of Dermatology, 86, 741.

Suerig, K.C. \& Siefert, F.E. (1964) Pseudoxanthoma elasticum and sickle cell anaemia. Archives of Internal Medicine, 113, 135. 